\title{
O PROGRAMA DE INCLUSÃO NA UNESP: VALORES, CONTRADIÇÕES E AÇÕES AFIRMATIVAS
}

\author{
Mário Sérgio VASCONCELOS ${ }^{1}$ \\ Eduardo GALHARDO ${ }^{2}$
}

Resumo: Este artigo tem por objetivo mais amplo realizar uma reflexão sobre o processo de implantação de políticas afirmativas no ensino superior. Mais especificamente, busca descrever e fazer alguns apontamentos sobre o Projeto de Inclusão desenvolvido na Universidade Estadual Paulista (UNESP), a partir de 2014, por meio do Sistema de Reserva de Vagas da Educação Básica Pública. Com essa perspectiva, apresentamos dados sobre o processo inclusivo, o perfil dos estudantes e ações voltadas para a permanência estudantil que dão suporte à inclusão na UNESP. Finalmente, relatamos o esboço de uma pesquisa em andamento que tem por finalidade compreender e avaliar os impactos e consequências deste processo de inclusão. As reflexões preliminares realizadas possibilitam apontar alguns resultados positivos e indicam que são necessárias ações institucionais integradas para se manter uma política inclusiva digna e condizente com os princípios de qualidade que devem orientar os serviços de uma Universidade Pública.

Palavras-chave: Ações afirmativas. Inclusão. Ensino superior. Permanência estudantil. UNESP.

"Pessoas pertencidas de abandono me comovem" (Manoel de Barros)

\section{INTRODUÇÃO}

A política educacional brasileira vem, aos poucos, tentando contribuir para minimizar as históricas desigualdades sociais e raciais existentes no país por meio de ações que possam propiciar às "minorias" sociais oportunidades de inserção no ensino superior.

Com certeza essa não é uma tarefa fácil considerando os aspectos quantitativos e as defasagens qualitativas que envolvem a educação brasileira. Além disso, há que se considerar situações adversas de natureza política, econômica, ideológica, cultural e

${ }^{1}$ UNESP - Universidade Estadual Paulista. Faculdade de Ciências e Letras de Assis. Assis - SP - Brasil. 19806-900 - vascon@assis.unesp.br.

${ }^{2}$ UNESP - Universidade Estadual Paulista. Faculdade de Ciências e Letras de Assis. Assis - SP - Brasil. 19806-900 - egalhard@ assis.unesp.br. 
pedagógica que compõem a multiplicidade de fatores envolvidos nesse processo. Contudo, há mais de uma década, várias ações já se fazem presentes e atuantes no ensino superior, principalmente por meio da implantação de Políticas de Ações Afirmativas - PAAs (COSTA, 2009; LIMA; NEVES; BACELLAR E SILVA, 2014).

Em se tratando de investimentos públicos voltados para ações afirmativas governamentais dirigidas às universidades, busca-se assegurar a inclusão por meio de cotas e de programas de permanência estudantil que têm dentre os principais objetivos proporcionar condições que contribuam para evitar a retenção e a evasão visando à formação de profissionais qualificados para o mercado de trabalho. Mendes Junior (2014, p.32), afirma que:

\begin{abstract}
Para que esses objetivos de política educacional sejam atingidos plenamente é necessário que os recém-matriculados na universidade sejam capazes de progredir nos períodos até a graduação. Mesmo que evadam ao longo do curso, os alunos podem obter maiores retornos no mercado de trabalho em comparação com a situação de não terem ingressado no ensino superior. Porém, se estamos preocupados em maximizar os retornos educacionais, isto não é o bastante. Conseguir manter os alunos até a formatura torna-se então uma condição necessária para que a missão de uma instituição de ensino superior (IES) seja cumprida integralmente.
\end{abstract}

Desse modo, uma parcela do aparato institucional relacionado à política educacional brasileira tem procurado não somente fornecer subsídios para que esses objetivos sejam alcançados, mas também encontrar mecanismos que propiciem o acesso ao ensino superior à população economicamente mais vulnerável, principalmente os estudantes deste contingente populacional que frequenta escolas públicas. Diante deste cenário as Políticas de Ações Afirmativas (PAAs) ${ }^{3}$ e os Planos Plurianuais (PPAs) ${ }^{4}$ se configuram como algumas das estratégias que compõem a tentativa da democratização do acesso à educação. Para Neves, Raizer e Fachinetto (2007) tal ocorrência tem acarretado efetivamente a expansão da educação brasileira no ensino superior.

As Políticas de Ações Afirmativas tiveram seu principal marco, a nível nacional, em 29 de agosto de 2012, data em que a Presidência da República sancionou a Lei 12.711 (BRASIL, 2012), determinando que as instituições federais de educação superior

\footnotetext{
${ }^{3}$ Destacam-se os Cursinhos pré-vestibulares em IES, o PROUNI, o REUNI, o SISU, o PNAES, o PRONATEC e a Lei 12.711 (Cotas) (BRASIL, 2012).

4 Destacam-se o Estatuto da Igualdade Racial, Lei 12.288/2010 (BRASIL, 2010), o Programa de Enfrentamento ao Racismo Institucional (PCRI) (QUERINO, 2013) e o PROJOVEM.
} 
vinculadas ao Ministério da Educação deveriam reservar, em cada concurso seletivo para ingresso nos cursos de graduação, por turno e curso, no mínimo 50\% (cinquenta por cento) de suas vagas, para estudantes que tenham cursado integralmente o ensino médio em escolas públicas. Além disso, estabeleceu que em cada instituição federal de ensino superior, as vagas deverão ser preenchidas, por turno e curso, por autodeclarados pretos, pardos e índios, em proporção, no mínimo, igual a dos pretos, pardos e índios na população da unidade da federação onde está instalada a instituição, segundo o último censo do Instituto Brasileiro de Geografia Estatística - IBGE (BRASIL, 2012).

Embora a Lei Federal tenha sido decretada apenas em 2012, algumas instituições federais, estaduais e municipais de ensino superior já vinham tomando iniciativas em promover ações afirmativas. A primeira instituição de ensino superior no Brasil a adotar ações afirmativas em maiores proporções foi a Universidade Estadual do Rio de Janeiro (UERJ). Naquela universidade, no período de 2003 até 2012, ingressaram pelo sistema de cotas 16.607 estudantes. O sistema de cotas da UERJ estabelecia os seguintes percentuais para reserva de vagas: $20 \%$ para estudantes negros e indígenas, $20 \%$ para estudantes oriundos da rede pública de ensino e $5 \%$ para pessoas com deficiências e filhos de policiais civis, militares, inspetores de segurança ou administração penitenciária, mortos ou incapacitados por razão de serviço. Dos 16.607 alunos que ingressaram no programa de inclusão da UERJ, entre 2003 e 2012, 4738 (28,53\%) já se formaram e 4985 (30,01\%) evadiram (MENDES JUNIOR, 2014).

A partir da iniciativa da UERJ, outras universidades brasileiras deram início a programas de inclusão social. Todavia, mesmo com o sansão da Lei 12.711/2012 (BRASIL, 2012), que tem como objetivo principal minimizar e neutralizar os efeitos das discriminações interseccionais ${ }^{5}$ criando oportunidades equitativas de modo proativo, algumas instituições de nível superior ainda não adotaram a normativa inclusiva levando a vários debates sobre o assunto, seja no âmbito acadêmico bem como em outros seguimentos sociais, existindo posicionamentos favoráveis e desfavoráveis à implantação das políticas afirmativas de cotas nas universidades.

Convém lembrar que, em se tratando de ensino superior brasileiro, não é fácil ingressar em um curso em universidades públicas, principalmente para um estudante oriundo da educação pública (fundamental e médio) que ao longo dos anos passa por grandes índices de desestabilizações e investimentos abaixo do necessário. Assim, para

5 Marcadores sociais de raça/etnia, gêneros, idades, classe social, nacionalidade, etc. (MELLO; GONÇALVES, 2010). 
estudantes de escolas públicas adentrarem e até mesmo almejarem um ensino superior em universidades públicas, chega por vezes ser meramente um desejo. Diante de tal realidade a parcela de estudantes de escolas públicas que ingressaram em universidades públicas ainda é pequena quando comparada ao índice de estudantes que tiveram condições de estudarem em escolas e colégios privados. De acordo com Castro (2001 apud VASCONCELOS; SILVA, 2005), há uma grande disparidade que torna desigual a competição por uma vaga em instituições públicas de ensino, pois a maioria dos estudantes de escolas privadas passa por uma preparação para o vestibular, além de muitos terem condições financeiras que os possibilita fazerem cursos pré-vestibulares. Desse modo, não se pode negligenciar que fatores socioeconômicos interferem direta e indiretamente na aquisição de uma vaga nas universidades públicas, além de ter efeitos preponderantes na própria formação educacional dos estudantes (RISTOFF, 2014).

Considerando as relações entre aspectos socioeconômicos, culturais e políticas afirmativas, pesquisas vêm sendo desenvolvidas com o objetivo de se compreender melhor as resistências, impactos e consequências da implantação de programas de inclusão para estudantes de escolas públicas em universidades públicas. Nesse sentido, algumas pesquisas quantitativas e/ou qualitativas realizadas nas universidades que adotaram o sistema de cotas para estudantes de escolas públicas, trazem dados expressivos ao tratarem de discussões que incluem o preconceito, a reparação de direitos, o desempenho e a permanência, retenção e evasão dos ingressantes por esse sistema (MENIN et al., 2008; JÚNIOR, 2014). De um modo geral, tais estudos descrevem realidades distintas, mas a maioria nos mostra que a implantação das PAAs tem apontado resultados positivos (VELLOSO, 2009; WINTHER; CERVI, 2013; MENDES JUNIOR, 2014; VIBETTO, 2014). Alguns avaliam, a partir da comparação de grupos focais compostos de estudantes não cotistas e cotistas, os coeficientes de rendimento $(\mathrm{CR})$ e as taxas de graduação e evasão. Resultados demonstram que os cotistas tendem a atribuir um alto valor aos cursos que ingressaram, por isto, persistem em maior proporção na universidade a despeito de menores coeficientes de rendimentos médios (MENDES JUNIOR, 2014). Outro fator frequentemente estudado é o perfil socioeconômico dos alunos ingressantes em comparação com o seu desempenho no vestibular e/ou nas disciplinas da graduação. As análises indicam que as desigualdades sociais interferem decisivamente no processo educacional, inclusive na escolha de carreiras de maior ou menor prestígio social (SOUZA, 2012; ZAGO, 2006). 
De um modo geral, constatamos que a maioria dos estudos aponta tanto aspectos positivos como negativos relacionados ao processo de inclusão, porém quase sempre os pontos positivos são suportes para apresentarem justificativas contundentes a favor da implantação de ações afirmativas que possibilitem a superação dos possíveis obstáculos para inserção ao ensino superior.

\section{A proposta de inclusão na UNESP}

Embora as universidades estaduais paulistas (UNESP, UNICAMP e USP) há mais de três décadas desenvolvam algumas ações visando favorecer a inclusão e permanência estudantil (cursinhos pré-vestibular, inscrição gratuita em vestibular, bolsas de apoio acadêmico, moradias estudantis, auxílios aluguel, restaurantes universitários, subsídios alimentação, auxílio transporte, etc.) e tenham em seu quadro um grande número de estudantes oriundos de escolas públicas, propostas de inclusão com o perfil de cotas somente foram concretizadas a partir de 2013, quando o governo do Estado de São Paulo solicitou, por meio do Programa Paulista de Inclusão Social no Ensino Superior (PPISES), que as três universidades implementassem ações afirmativas para promover a inclusão de alunos em condições de vulnerabilidade socioeconômica nos seus cursos de graduação, mediante o acolhimento, em $50 \%$ de suas vagas, de alunos de escolas públicas, guardando, dentre estes, a parcela de $35 \%$ dos grupos étnicos preto, pardo e índio.

Após vários estudos realizados por comissões compostas por docentes da UNESP, USP e UNICAMP e especialistas indicados pelo Governo do Estado de São Paulo, foi elaborada a proposta do Programa de Inclusão com Mérito no Ensino Superior Público Paulista (PIMESP), no qual estava previsto que as universidades estaduais tivessem ao menos $50 \%$ das matrículas, em cada turno, com alunos que cursavam integralmente o Ensino Médio em Escolas Públicas e, dentre os 50\%, o percentual de pretos, pardos e indígenas deveria ser, no mínimo, aquele verificado pelo IBGE no Censo demográfico de 2010 (BRASIL, 2010) (35\%). Estas metas deveriam ser atingidas até 2014 .

O Conselho Universitário da Universidade Estadual Paulista "Júlio de Mesquita Filho" (UNESP), buscando atender à solicitação do Governo do Estado de São Paulo e se aprofundar na discussão sobre as propostas de inclusão, após vários debates bastante polêmicos envolvendo o PPISES e o PIMESP, em agosto de 2013, aprovou, semelhante 
à UNICAMP e à USP ${ }^{6}$, proposta de inclusão diferente do PIMESP. O projeto de inclusão aprovado pela UNESP prevê o seguinte:

- 50\% das vagas, para cada curso e turno, dos cursos de graduação da UNESP devem ser preenchidas por estudantes que cursaram integralmente o ensino médio em escolas públicas;

- do total de vagas a serem ocupadas por estudantes oriundos de escolas públicas, $35 \%$ deverão ser reservadas para pretos, pardos e índios;

- no prazo de 5 (cinco) anos a universidade deverá a atingir a meta de inclusão de $50 \%$ de estudantes, sendo $15 \%$ em 2014, $25 \%$ em 2015, 35\% em 2016, 45\% em 2017 e $50 \%$ em 2018;

- a metodologia adotada para a inclusão é o processo classificatório do vestibular, através de Sistema de Reserva de Vagas para a Escola Básica Pública (SRVEBP), com aproveitamento dos candidatos até o limite de vagas fixadas para cada curso e turno.

\section{O ingresso de estudantes na UNESP pelo Sistema de Reserva de Vagas para a Educação Básica Pública (SRVEBP)}

Em 2014 a UNESP ofereceu no vestibular de inicio de ano 7.259 vagas, distribuídas em 171 opções de cursos, em 23 cidades: Araçatuba (155 vagas), Araraquara (855 vagas), Assis (405 vagas), Bauru (1.045 vagas), Botucatu (600 vagas), Dracena (40 vagas), Franca (400 vagas), Guaratinguetá (310 vagas), Ilha Solteira (270 vagas), Itapeva (80 vagas), Jaboticabal (280 vagas), Marília (475 vagas), Ourinhos (90 vagas), Presidente Prudente (640 vagas), Registro (40 vagas), Rio Claro (490 vagas), Rosana (80 vagas), São João da Boa Vista (40 vagas), São José do Rio Preto (460 vagas), São José dos Campos (120 vagas), São Paulo (184 vagas), São Vicente (80 vagas) e Tupã (120 vagas). No vestibular realizado no mês de junho, de 2014, ingressaram mais 420 estudantes em 5 cidades: Bauru (40 vagas), Dracena (40 vagas), Ilha Solteira (200 vagas), Registro (40 vagas) e Sorocaba (100 vagas). Portanto, em 2014, ingressaram na UNESP 7.679 alunos. Pelo sistema de Sistema de Reserva de Vagas para Educação Básica Pública (SRVEBP) ingressaram 1.197 estudantes (15\%) alunos que cursaram todo o ensino médio em escola pública. Destes, 412 autodeclarados pretos pardos ou indígenas (SRVEBP+PPI).

No Vestibular 2015, o Sistema de Reserva de Vagas para a Educação Básica Pública (SRVEBP) garantiu um mínimo de $25 \%$ das vagas de cada curso para alunos que tenham feito todo o ensino médio em escola pública. Isso ampliou a proporção

\footnotetext{
${ }^{6}$ As propostas aprovadas pela UNESP, UNICAMP e USP são distintas entre si e diferentes do PIMESP.
} 
destes alunos nos cursos da UNESP, que até 2013 era de aproximadamente $36 \%$ das vagas oferecidas.

Em 2015 a UNESP ofereceu 7.271 (sete mil, duzentas e setenta e uma) vagas para os cursos que iniciaram no primeiro semestre de 2015 e 420 vagas para o vestibular de meio do ano. No total foram 7691 vagas. Consequentemente, houve a seguinte distribuição de vagas: 5.740 (cinco mil, setecentas e quarenta) vagas para o Sistema Universal (SU); 1.951 (um mil, novecentos e cinquenta e uma) vagas para o Sistema de Reserva de Vagas para Educação Básica Pública (SRVEBP). Destas, 595 (quinhentas e noventa e cinco) vagas foram destinadas aos candidatos que se autodeclararem pretos, pardos ou indígenas (SRVEBP+PPI).

Considerando os dados de 2014 e 2015, o total de ingressantes na UNESP neste período foi de 15.370 estudantes. Pelo SRVEBP, ingressaram 3.148 estudantes. Deste total, 1.007 foram reservadas para pretos, pardos e índios.

Quadro 1 - Distribuição do número de estudantes por sistema de ingresso nos vestibulares da UNESP de 2014 e 2015

\begin{tabular}{|crrr|}
\hline Sistema de Ingresso & $\mathbf{2 0 1 4}$ & $\mathbf{2 0 1 5}$ & Totais \\
\hline Total de Vagas & 7679 & 7691 & 15370 \\
\hline Sistema Universal & 6482 & 5740 & 12222 \\
\hline SRVEBP & 785 & 1356 & 2141 \\
\hline SRVEBP (PPI) & 412 & 595 & 1007 \\
\hline Total do SRVEBP & 1197 & 1951 & $\mathbf{3 1 4 8}$ \\
\hline
\end{tabular}

Fonte: Dados informados pela PROGRAD e COPE (VASCONCELOS; GALHARDO, 2015a).

\section{O perfil do estudante da UNESP}

Como afirmamos, a UNESP tem atualmente 34 unidades em 24 cidades. Desde a sua criação, em 1976, vem gradativamente aumentando o número de cursos e de estudantes. Em 1990, já contava com 17.199 alunos de graduação e, em 2000, este contingente subiu para 23.603 alunos. Entre 2002 e 2014 houve um aumento de aproximadamente 12.000 alunos. No final de 2014 contava com 37.388 estudantes de 
graduação. O aumento gradativo de alunos no período de 2002 até 2014 pode se melhor visualizado na Figura 1.

Figura 1 - Estudantes matriculados nos cursos de graduação da UNESP

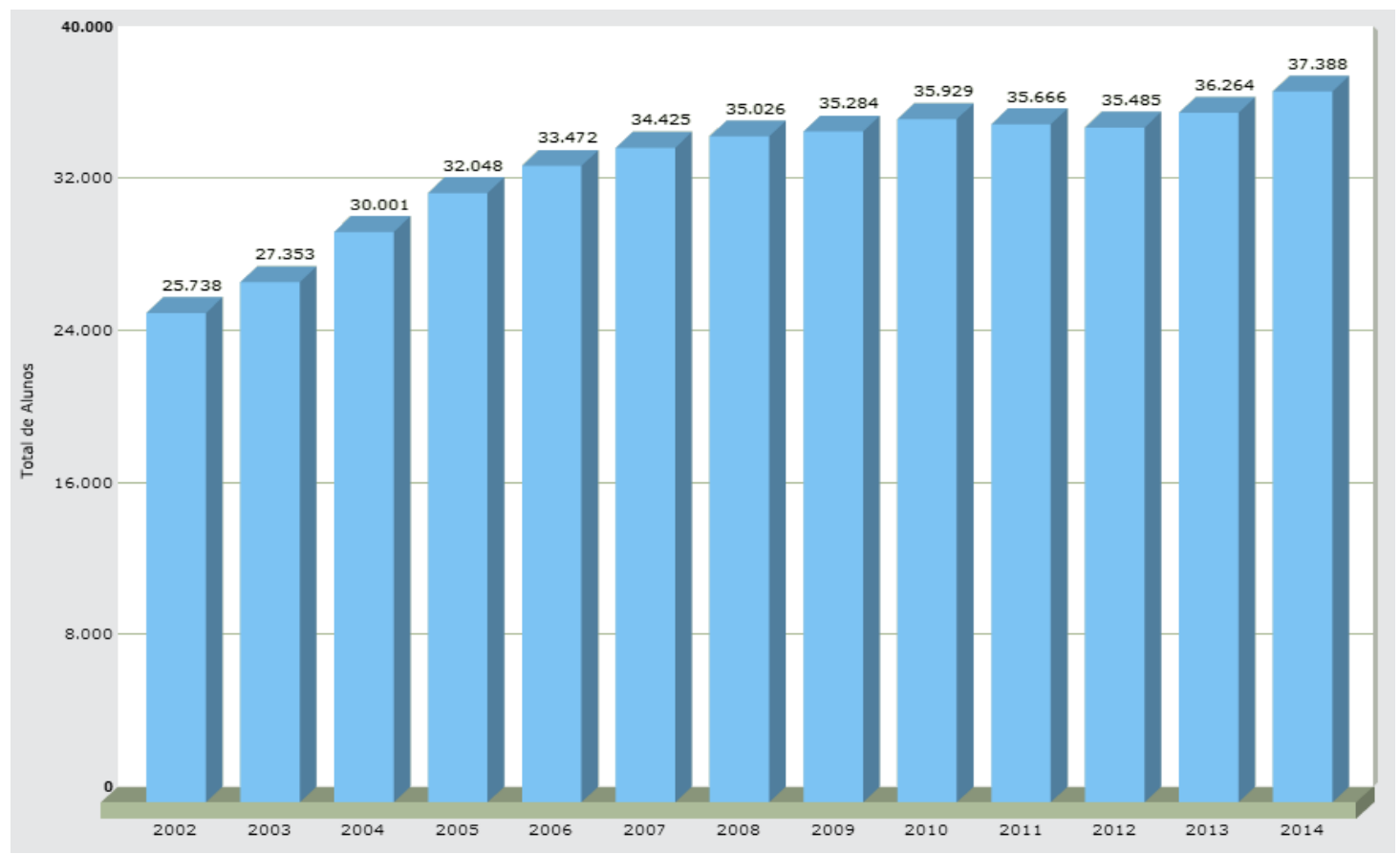

Fonte: Anuário Estatístico de 2015 (SÃO PAULO, 2015).

Embora a UNESP tenha em seu quadro um grande contingente de estudantes oriundos de escolas públicas, a inovação inclusiva, estabelecendo percentuais de alunos de escola pública por curso e turma, é uma variável que, a médio prazo, estará influenciando o perfil de estudantes da UNESP. O principal motivo desta hipótese está no fato de que o programa de inclusão adotado passou a considerar o grupo de alunos ingressantes que cursaram integralmente o Ensino Médio em Escola Pública.

Podemos observar, a seguir, na Figura 2, a sequência histórica, de 2010 a 2015, da distribuição dos alunos matriculados no $1^{\circ}$ ano dos cursos de graduação da UNESP, por origem administrativa do Ensino Médio, considerando os grupos que cursaram integralmente o ensino médio em escolas públicas e os que fizeram um ou mais anos em escolas particulares. 
Figura 2 - Número de alunos ingressantes por origem administrativa do ensino médio de 2010 a 2015

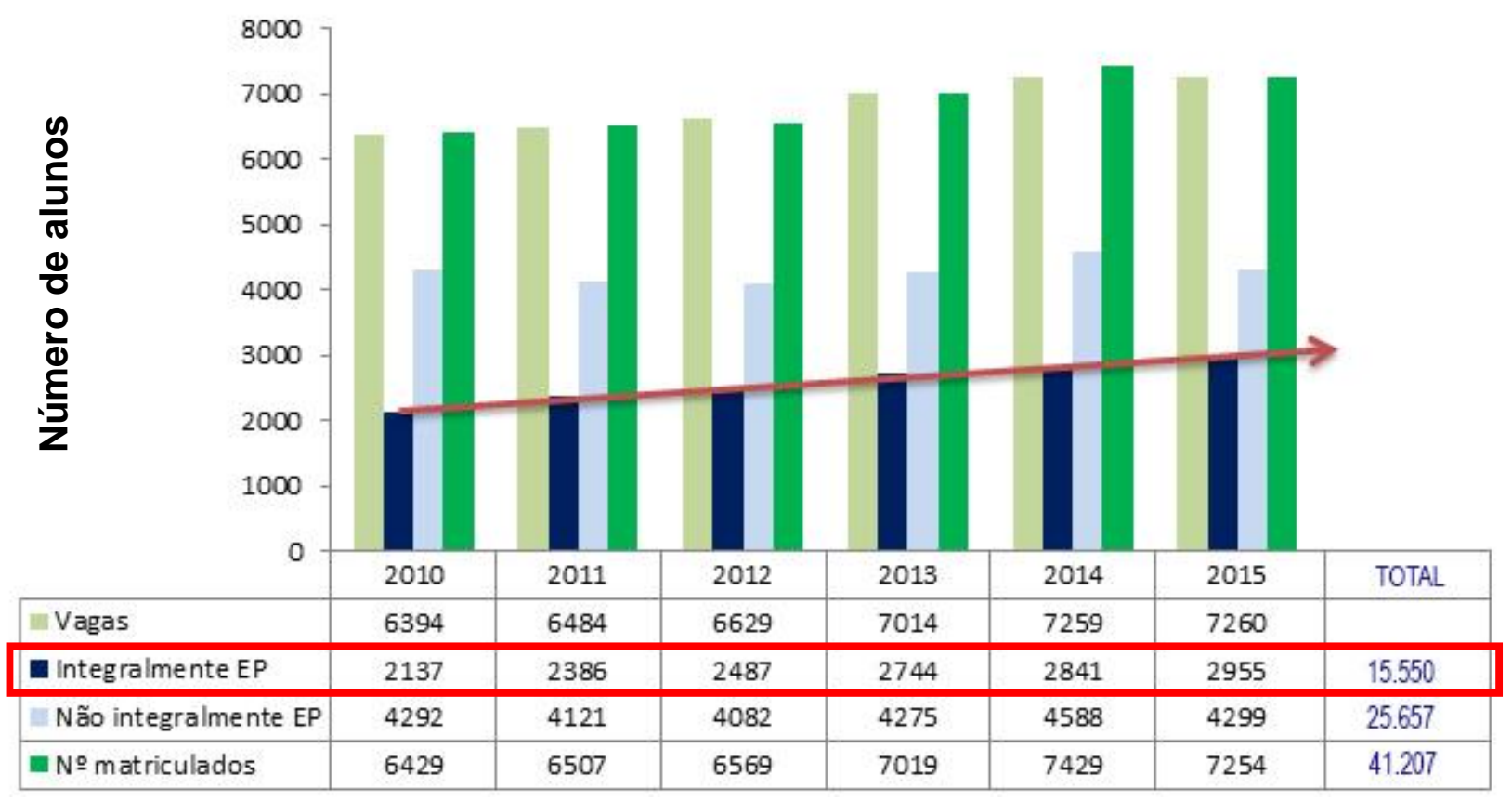

Fonte: Dados elaborados pela VUNESP (AZEVEDO, 2015).

Observando a Figura 2, pode-se constatar, somando-se os dados da segunda linha "Integralmente EP (Escola Pública)", que nos últimos seis anos a UNESP absorveu $\mathbf{1 5 . 5 5 0}$ alunos que frequentaram integralmente a escola pública e que esse aumento é gradativo e anual. Segundo Azevedo (2015), a análise do ingresso de estudantes na UNESP demonstra que:

Em relação ao processo seletivo de 2010 a universidade recebeu em 2014 um total de 708 alunos a mais, finalizando a matrícula com 2.841 alunos que cursaram integralmente o Ensino Médio em Escolas Públicas, representando $38,34 \%$ dos alunos matriculados ou $39,14 \%$ das vagas oferecidas e em 2015 a universidade recebeu 818 alunos a mais, representando $40,7 \%$ dos alunos matriculados ou em vagas oferecidas.

Por ocasião do período de inscrição no Vestibular UNESP, em questionário socioeconômico apresentado aos candidatos, estes responderam, entre outras, duas questões relativas à renda familiar e ao número de pessoas que vivem com a renda declarada. Analisando as respostas dos alunos matriculados nos diferentes cursos de 
graduação oferecidos pela UNESP, é possível calcular, mantendo-se uma correlação entre as duas respostas, a renda per capita do aluno matriculado.

Para fins de apresentação dos resultados e da análise dos dados, o universo dos alunos matriculados foi reagrupado em três grupos: o primeiro com renda per capita até 1,50 salários mínimos (possíveis candidatos ao programa de bolsa e auxílios de permanência estudantil), o segundo grupo com os alunos matriculados que declararam renda per capita familiar de 1,51 a 2,00 salários mínimos e o terceiro grupo com renda per capita superior a 2,00 salários mínimos. A Figura 3 apresenta a distribuição de alunos matriculados no primeiro ano de graduação na UNESP nos diferentes grupos de renda familiar per capita.

Figura 3 - Número de alunos ingressantes por intervalo de renda familiar per capita, por ano de ingresso e número de vagas

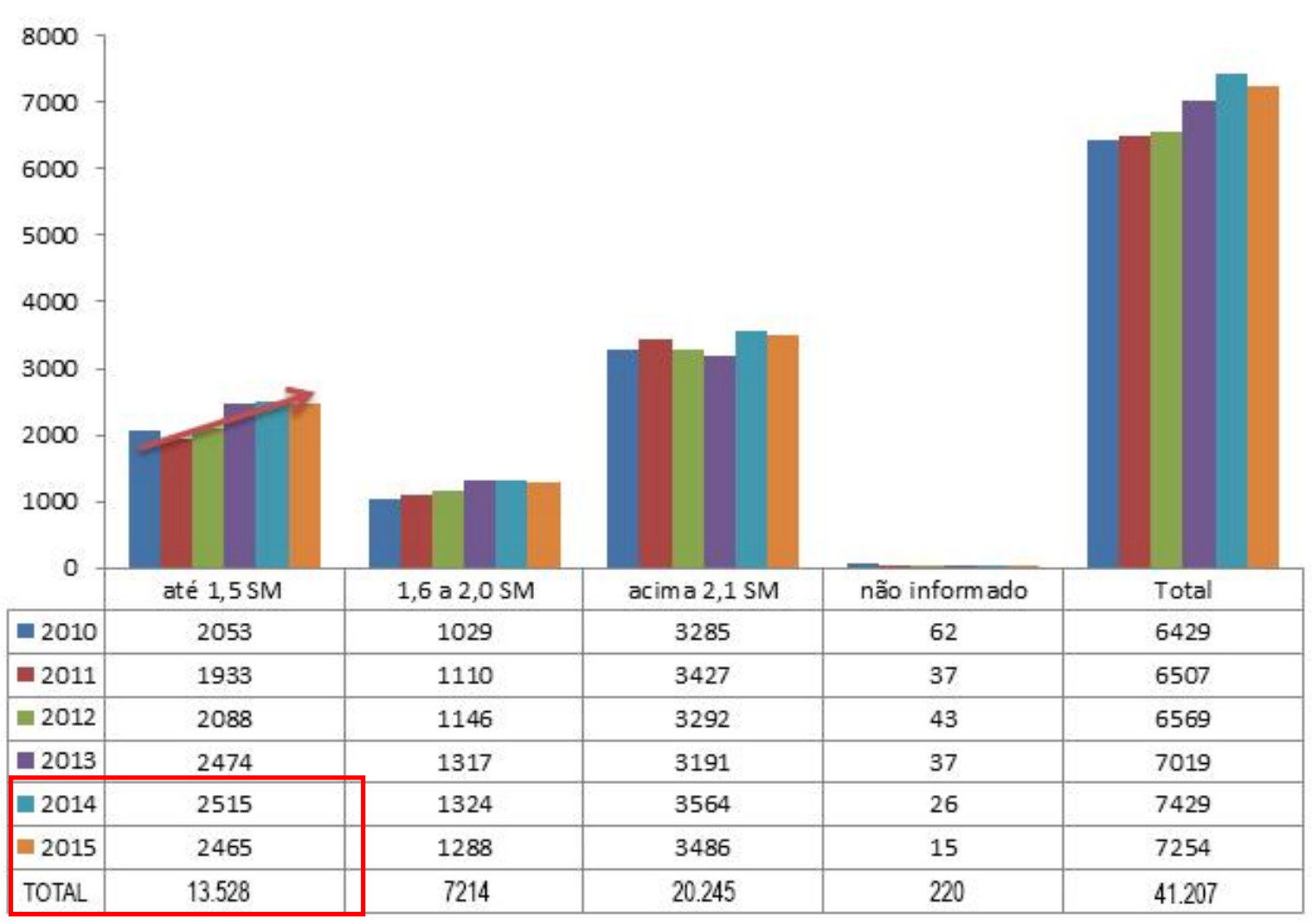

Fonte: Dados elaborados pela VUNESP (AZEVEDO, 2015). 
Pela análise da sequência histórica dos processos seletivos de 2010 a 2015, relativa aos dados obtidos das declarações dos candidatos inscritos no Vestibular, conclui-se que, considerando apenas o atendimento ao critério de renda familiar per capita de até 1,5 salários mínimos, a UNESP, em 2014, recebeu 2.515 alunos (33,85\% dos ingressantes) e, em 2015, recebeu 2.465 (33,98\%) dos ingressantes na condição descrita. Se somarmos (na primeira coluna vertical) o montante de alunos que ingressaram na UNESP com o perfil sócio econômico de renda familiar per capita de até 1,5 salários, entre 2010 e 2015, temos no período o total de 13.528 ingressantes.

\section{A permanência estudantil na UNESP}

Conforme afirma Ristoff (2014), fatores socioeconômicos interferem direta e indiretamente na aquisição de uma vaga nas universidades públicas, na formação dos estudantes e nos índices de evasão. Visto que historicamente, cada vez mais, uma grande parcela de estudantes que ingressa na UNESP vem de escolas públicas e de famílias com renda per capita familiar de até 1,5 salários mínimos, se intensifica a hipótese de que a inclusão é um dos fatores que contribuí para reforçar o perfil de vulnerabilidade socioeconômica dos estudantes da universidade. Desse modo, em função deste perfil, não se pode negligenciar que a política de inclusão, para se consolidar de fato como inclusiva e não apenas como mecanismo de ingresso no ensino superior, deve ser acompanhada de outras ações afirmativas que possibilitem ao estudante permanecer na instituição até o final do curso. Trata-se da necessidade de um conjunto de ações articuladas que incluem auxílios socioeconômicos e novas arquiteturas pedagógicas que tenham como princípio a diversidade e que possam favorecer a criação de uma "cultura de emancipação".

Há mais de duas décadas a UNESP desenvolve ações voltadas para a assistência ao estudante. Bolsas de Apoio Acadêmico, Programa Adote um Aluno, Moradias Estudantis, Auxílios Aluguel, Restaurantes Universitários e Subsídios Alimentação são algumas destas ações. Porém, uma política de inclusão impõe novas demandas, impulsiona reivindicações e fortes mobilizações de pessoas e instituições diretamente relacionadas a esse cenário. Foi num contexto com estas características, com intensa participação dos estudantes, que o Conselho Universitário da UNESP criou, em agosto de 2013, a Coordenadoria de Permanência Estudantil (COPE) e a Comissão Permanente 
de Permanência Estudantil (CPPE) com a finalidade de dar melhor atendimento aos estudantes.

A COPE foi implantada com o propósito de elaborar, planejar, acompanhar e avaliar, em conjunto com CPPE, políticas, programas, metas e ações que tenham por objetivo promover a igualdade de oportunidades aos estudantes que estejam em situação de vulnerabilidade socioeconômica, contribuindo para a redução de índices de retenção e evasão na universidade. Os principais objetivos da COPE e CPPE são: a) Planejar ações para receber alunos que ingressarem na UNESP pelo Programa de Inclusão por meio do Sistema de Reserva de Vagas da Educação Básica Pública (SRVEBP); b) Introduzir na UNESP as diretrizes do Plano Nacional de Assistência Estudantil PNAES (BRASIL, 2010), que visa, principalmente, atender estudantes oriundos da rede pública de educação básica com renda per capita de até 1,5 salários mínimos; c) atender as demandas de permanência relacionadas à implantação de novos cursos; d) consolidar a Política de Permanência Estudantil na UNESP.

Embora as ações da UNESP ainda estejam muito aquém de promoverem uma política emancipatória e consolidada de inclusão e permanência estudantil ${ }^{7}$, atualmente a instituição oferece aos estudantes (com vulnerabilidade socioeconômica) moradia estudantil, restaurante universitário, bolsa de apoio acadêmico e extensão, auxílio aluguel, subsídio alimentação, bolsa especial e auxílio estágio ${ }^{8}$.

A análise dos dados do processo seletivo para atribuição de auxílios de permanência estudantil em 2014 e 2015 permitiu realizar um estudo mais aprofundado das solicitações desses estudantes e dos impactos do programa de inclusão pelo Sistema de Reserva de Vagas da Educação Básica Pública (SRVEBP). Nos Quadros 2 e 3 são apresentados, respectivamente, em relação aos anos de 2014 e 2015, dados referentes à quantidade de estudantes por categoria de auxílios de permanência estudantil, incluindo os ingressantes.

\footnotetext{
${ }^{7}$ Inclusive porque a COPE e a CPPE começaram, de fato, a funcionar em 2014. Novas modalidades de auxílios socioeconômicos e apoios acadêmicos estão em discussão nos órgãos colegiados competentes.

${ }^{8}$ Moradia Estudantil (1240 vagas), Restaurante Universitário (5470 refeições dia), Bolsa de Apoio Acadêmico e Extensão (R\$ 350,00), Auxílio Aluguel (R\$ 230,00), Subsídio Alimentação (R\$ 75,00), Bolsa para alunos com deficiência ( $\mathrm{R} \$ 450,00)$, Auxílio Estágio ( $\mathrm{R} \$ 350,00)$. Os alunos com extrema dificuldade socioeconômica podem acumular o Auxílio Socioeconômico, Auxílio Aluguel e Subsídio Alimentação, perfazendo o total de R\$ 655,00.
} 
Quadro 2 - Distribuição de estudantes por categoria de auxílios de permanência estudantil em 2014

\begin{tabular}{|c|c|c|c|c|c|c|c|}
\hline Estudantes & $\begin{array}{c}\text { Contemplados } \\
\text { BAAE }\end{array}$ & $\begin{array}{c}\text { Contemplados } \\
\text { Auxíio } \\
\text { Aluguel }\end{array}$ & $\begin{array}{c}\text { Contemplados } \\
\text { BAAE e } \\
\text { Auxíio } \\
\text { Aluguel }\end{array}$ & $\begin{array}{c}\text { Contemplados } \\
\text { Moradia } \\
\text { Estudantil }\end{array}$ & $\begin{array}{c}\text { Contemplado } \\
\text { s Moradia } \\
\text { Estudantil e } \\
\text { BAAE }\end{array}$ & $\begin{array}{c}\text { Migraram ou } \\
\text { não foram } \\
\text { contemplados } \\
\text { devido aos } \\
\text { critérios }\end{array}$ & Inscritos \\
\hline Veteranos & 640 & 320 & 111 & 369 & 289 & 178 & 1907 \\
\hline $\begin{array}{c}\text { Ingressantes } \\
\text { SRVEBP9 }\end{array}$ & 272 & 76 & 55 & 58 & 146 & 28 & 635 \\
\hline $\begin{array}{c}\text { Ingressantes } \\
\text { SU }^{10}\end{array}$ & 153 & 47 & 24 & 40 & 59 & 12 & 335 \\
\hline Total & 1065 & 443 & 190 & 467 & 494 & 218 & 2877 \\
\hline
\end{tabular}

onte: Coordenadoria de Permanência Estudantil (VASCONCELOS; GALHARDO, 2014).

Quadro 3 - Distribuição de estudantes por categoria de auxílios de permanência estudantil em $2015^{11}$

\begin{tabular}{|c|c|c|c|c|c|c|c|c|}
\hline Estudantes & $\begin{array}{c}\text { Contempla- } \\
\text { dos } \\
\text { BAAE }\end{array}$ & $\begin{array}{c}\text { Contempla- } \\
\text { dos Auxíio } \\
\text { Aluguel }\end{array}$ & $\begin{array}{c}\text { Contempla- } \\
\text { dos BAAE e } \\
\text { Auxíli } \\
\text { Aluguel }\end{array}$ & $\begin{array}{c}\text { Contempla- } \\
\text { dos Moradia } \\
\text { Estudantil }\end{array}$ & $\begin{array}{c}\text { Contempla- } \\
\text { dos BAAE e } \\
\text { Moradia } \\
\text { Estudantil }\end{array}$ & Migraram & $\begin{array}{c}\text { Não } \\
\text { contempla- } \\
\text { dos* }\end{array}$ & Inscritos \\
\hline $\begin{array}{c}\text { Veteranos } \\
\leq 2013\end{array}$ & 429 & 213 & 100 & 268 & 238 & 54 & 404 & 1706 \\
\hline $\begin{array}{c}\text { SU } \\
2014-2015\end{array}$ & 288 & 77 & 81 & 58 & 102 & 16 & 265 & 887 \\
\hline $\begin{array}{c}\text { SRVEBP } \\
2014-2015\end{array}$ & 514 & 124 & 148 & 84 & 256 & 24 & 289 & 1439 \\
\hline Total & 1231 & 414 & 329 & 410 & 596 & 94 & $958 *$ & 4032 \\
\hline
\end{tabular}

* Entre os não contemplados, 361 possuíam renda per capita familiar superior a 1,5 salários mínimos. 96 devido ao rendimento acadêmico e 504 por razões variadas, como por exemplo, documentação incompleta ou não comparecimento à entrevista realizada por Assistente Social.

onte: Coordenadoria de Permanência Estudantil (VASCONCELOS; GALHARDO 2015b).

\footnotetext{
${ }^{9}$ Sistema de Reserva de Vagas da Educação Básica Pública.

${ }^{10}$ Sistema Universal.

${ }^{11}$ Temos que ressaltar que a adoção de uma metodologia de registro dos processos de seleção por meio de ferramentas informacionais permitiu o aprimoramento do registro dos auxílios concedidos e, consequentemente, destacar aspectos importantes referentes ao processo de concessão de auxílios de permanência estudantil em 2014 e 2015. Por exemplo, em 2014, registramos somente os estudantes que tiveram sua inscrição aceita (após verificação dos documentos e realização das entrevistas) e, em 2015, foram tabulados os dados de todos os alunos que solicitaram auxílios de permanência estudantil.
} 
Os quadros 3 e 4 indicam que houve um impacto crescente na demanda de auxílios relacionados à permanência estudantil depois da implantação do programa de inclusão na UNESP por meio do SRVEBP. O programa prevê que no prazo de cinco anos a universidade deverá atingir a meta de inclusão de 50\% de estudantes, sendo $15 \%$ em 2014, 25\% em 2015, 35\% em 2016, $45 \%$ em 2017 e 50\% em 2018. Se somarmos o número de estudantes que ingressaram por meio do SRVEBP e que receberam pelo menos uma modalidade de auxílio, em 2014, estes totalizaram 607 dentre 2659, portanto 23\% dos contemplados. Em 2015 (com o aumento da cota de inclusão de 15\% para 25\%) os alunos do SRVEBP contemplados com pelo menos uma modalidade de auxílio foram 1150 dentre 3074, o que representa $37 \%$ do total de estudantes contemplados. Portanto, entre 2014 e 2015, houve um aumento de $14 \%$ na demanda de auxílios de permanência estudantil quando observado os estudantes que ingressaram por meio do SRVEBP. Seguindo esta tendência, a ampliação do ingresso de estudantes pelo SRVEBP até o ano de 2018 - ano no qual teremos 50\% de egressos da escola pública que ingressarão em todos os cursos de graduação da UNESP - provavelmente representará uma demanda ascendente relacionada aos auxílios de permanência estudantil.

\section{A pesquisa (em andamento) sobre a inclusão na UNESP ${ }^{12}$}

Como afirmamos no início deste texto, pesquisas vêm sendo desenvolvidas com o objetivo de se compreender melhor as resistências, contradições, impactos e consequências da implantação de programas de inclusão para estudantes de escolas públicas em universidades públicas. São pesquisas quantitativas e/ou qualitativas realizadas nas universidades que adotaram o sistema de cotas. Os resultados destes estudos trazem dados expressivos por tratarem de discussões que incluem a reparação de direitos, o desempenho, a permanência, retenção e evasão de estudantes de ingressaram por meio desse sistema (MENIN et al., 2008; MENDES JUNIOR, 2014). Tais dados, além de possibilitarem uma avaliação dos programas de inclusão, têm subsidiado debates fundamentais que, em alguns casos, contribuem para desconstruir preconceitos relacionados ao cenário da inclusão. Por isso, julgamos pertinente realizar uma pesquisa para acompanhar os impactos e efeitos da implantação do Programa de Inclusão na UNESP.

\footnotetext{
12 Esta pesquisa conta com a colaboração do bolsista de Iniciação Científica Edgar Bendahan Rodrigues (bolsa atribuída pela Prograd/UNESP).
} 
Esta pesquisa em andamento, de caráter descritivo, versa sobre as relações entre o perfil e o rendimento acadêmico dos estudantes que ingressaram na UNESP pelo SRVEBP. Os objetivos definidos para este estudo foram:

- Verificar o Coeficiente de Rendimento Escolar (CR) dos alunos que ingressaram na UNESP por meio do SRVEBP (objetivo relacionado à média das notas das disciplinas cursadas);

- Realizar uma análise comparativa entre o Coeficiente de Rendimento (CR) dos alunos que ingressaram pelo SRVEBP e alunos que ingressaram pelo Sistema Universal; -Verificar o Coeficiente de Desempenho Escolar (CD) dos alunos que ingressaram na UNESP por meio do SRVEBP; (objetivo relacionado ao percentual de aproveitamento em relação ao total de disciplinas cursadas);

- Realizar uma análise comparativa entre o Coeficiente de Desempenho (CD) dos alunos que ingressaram pelo SRVEBP e alunos que ingressaram pelo Sistema Universal;

- Verificar a média de frequência dos alunos que ingressaram pelo SRVEBP;

- Realizar uma análise comparativa entre as Taxas de Evasão anual (TE) considerando as duas formas de ingresso;

- Realizar uma análise comparativa entre a média de frequência dos alunos que ingressaram pelo SRVEBP e alunos que ingressaram pelo Sistema Universal;

- Verificar, a partir de 2017, o percentual de alunos que ingressaram pelo SRVEBP e que concluem o curso (Taxa de Graduação - TG);

- Realizar uma análise comparativa entre a Taxa de Graduação (TG) dos ingressantes pelo SRVEBP e dos alunos que ingressaram pelo Sistema Universal;

- Realizar uma análise comparativa entre o perfil socioeconômico do estudante e o Coeficiente de Rendimento (CR);

- Realizar análise comparativa entre o perfil socioeconômico e as Taxas de Evasão (TE) e Taxa de Graduação (TG).

Neste estudo serão objetos de análise os dados referentes a todos os estudantes que ingressaram e que ingressarão na UNESP, de 2014 a 2018, pelo Sistema de Reserva de Vagas da Escola Básica Pública (SRVEBP) e estudantes que ingressaram pelo Sistema Universal. Todos os dados serão coletados por meio do Sistema de Graduação da UNESP (SGA). O procedimento será de análise comparativa dos dados tendo por base cada objetivo proposto.

Embora ainda não tenhamos dados conclusivos, pois estamos em fase inicial de análise dos dados, julgamos importante divulgar alguns resultados preliminares, obtidos por meio do SGA, referentes aos egressos de Escolas Públicas (EPs) que ingressaram na UNESP em 2014. Neste ano houve 2227 estudantes ingressantes de EPs, o que representa $38,8 \%$ do total de 7259 vagas oferecidas na UNESP. Fizemos também uma análise um pouco mais detalhada dos dados de 590 estudantes de EPs que ingressaram 
pelo SRVEBP e que foram contemplados com algum tipo de auxílio relacionado à permanência estudantil. Estes dados podem ser observados no Quadro 4.

Quadro 4 - Dados obtidos no sistema de Gestão Acadêmica referentes aos estudantes ingressantes na UNESP egressos da Escola Pública e do SRVEBP

\begin{tabular}{|c|c|c|}
\hline SGA-UNESP 2014 & Egressos da Escola Pública & SRVEBP + PPI \\
\hline N & 2227 & 590 \\
\hline MATRICULADOS & 1782 & 514 \\
\hline CANCELADOS (EVASÃO) & $445(20 \%)$ & $76(13 \%)$ \\
\hline MÉDIA DESEMPENHO & 83,1 & 85,6 \\
\hline MÉDIA FREQUÊNCIA & 87,1 & 89,4 \\
\hline COEFICIENTE RENDIMENTO & 6,14 & 6,30 \\
\hline
\end{tabular}

Fonte: Dados obtidos pela COPE (VASCONCELOS; GALHARDO, 2015b).

No Quadro 4 podemos observar que 76 (13\%) dentre os 590 alunos do SRVEBP e que foram contemplados com auxílios de permanência estudantil cancelaram a matrícula e/ou se evadiram da universidade. Por outro lado, 445 (20\%) dentre 2227 alunos de EPs cancelaram e/ou evadiram. Tais dados indicam que o cancelamento foi feito por $13 \%$ dos estudantes dos estudantes que entraram pelo sistema de reserva de vagas e que receberam auxílios de permanência estudantil em contraposição a $20 \%$ observados entre os egressos de escola pública que não foram subsidiados. Mesmo que preliminares, tais dados podem indicar que os auxílios de permanência estudantil são fundamentais para se evitar a evasão desse contingente de alunos.

Os dados referentes às médias de desempenho, frequência e coeficiente de rendimento dos estudantes que ingressaram pelo sistema de reserva foram ligeiramente melhores aos dados médios dos demais egressos da Escola Pública. No entanto, reiteramos, esses coeficientes são preliminares é a análise apresentada refere-se apenas ao ano de 2014. 


\section{Considerações finais}

As instituições de ensino superior brasileiras vêm, aos poucos, tentando contribuir para minimizar as históricas desigualdades sociais e raciais existentes no país por meio de ações afirmativas. Sabemos que essa não é uma tarefa fácil considerando situações adversas de natureza política, econômica, ideológica, cultural e pedagógica que compõem a multiplicidade de fatores envolvidos nesse processo. Contudo, há mais de uma década, várias ações já se fazem presentes no ensino superior, principalmente por meio da implantação de Políticas de Ações Afirmativas.

As Políticas de Ações Afirmativas tiveram um avanço substancial no ensino superior a partir da promulgação da Lei 12.711/2012 (BRASIL, 2012) que determinou que as instituições federais de educação devessem reservar, em cada concurso seletivo para ingresso nos cursos de graduação, por turno e curso, no mínimo 50\% (cinquenta por cento) de suas vagas, para estudantes que tenham cursado integralmente o ensino médio em escolas públicas. Com isso, aumentaram as iniciativas de universidades estaduais e municipais em promover processos de inclusão.

No estado de São Paulo, este processo teve início em 2013, quando a UNESP, UNICAMP e USP, por determinação do Governo do Estado, decidiram, após aquecidos debates, implantar projetos de inclusão. Tais debates foram marcados por posições antagônicas; contra ou a favor de tais projetos.

Do lado contrário os argumentos se centraram na ideia de que a inclusão representaria privilégio de alguns; a inclusão não é problema da universidade porque ela é decorrente da má qualidade do ensino fundamental e médio; a questão é de cunho econômico e não acadêmico; as cotas estimulam o preconceito racial; a inclusão promove o estigma em relação aos beneficiados; significa a perda de qualidade do ensino superior; representa uma injustiça ao direito individual legal; fere a competência e o mérito pessoal; é inconstitucional. De modo geral, tais posições poderiam ser categorizadas como de "igualdade legal e mérito individual".

Por outra lado, os argumentos favoráveis destacavam que: a não inclusão é fruto de discriminação, preconceito e estigma; é necessário dar um tratamento "igual" para a desigualdade social; não se pode reforçar o mito da democracia racial; as resistências às inclusões refletem as barreiras de classes sociais; é preciso superar o mito da democracia econômica; é necessário superar a "demarcação" de grupos étnicos raciais; há uma dívida histórica para com as "minorias"; a universidade pode favorecer a igualdade de direitos; é uma questão de justiça social; pesquisas mostram que não há 
uma diminuição na qualidade do ensino superior; a inclusão gera mobilidade social. De modo geral, tais posições poderiam ser categorizadas como aquelas que conduzem à "igualdade e justiça compensatória".

Apesar dos argumentos polarizados nos debates que ocorreram nas Universidades Estaduais Paulistas, a UNESP aprovou, em 2013, seu projeto de inclusão prevendo que $50 \%$ das vagas, para cada curso e turno, dos cursos de graduação da UNESP devem ser preenchidas por estudantes que cursaram integralmente o ensino médio em escolas públicas. Além disso, do total de vagas a serem ocupadas por estudantes oriundos de escolas públicas, $35 \%$ deverão ser reservadas para pretos, pardos e índios. O projeto, iniciado em 2014, deverá ser implantado de forma gradativa, no prazo de 5 (cinco) anos sendo 15\% em 2014, 25\% em 2015, 35\% em 2016, $45 \%$ em 2017 e 50\% em 2018. A metodologia adotada para a inclusão é o processo classificatório do vestibular, através de Sistema de Reserva de Vagas para a Escola Básica Pública (SRVEBP), com aproveitamento dos candidatos até o limite de vagas fixadas para cada curso e turno.

Em 2014 ingressaram na UNESP 7.679 alunos. Pelo sistema de Sistema de Reserva de Vagas para Educação Básica Pública (SRVEBP) ingressaram 1.197 estudantes (15\%) alunos que cursaram todo o ensino médio em escola pública. Destes, 412 autodeclarados pretos pardos ou indígenas (SRVEBP+PPI). Em 2015 a UNESP ofereceu 7.691 (sete mil, seiscentos e noventa e uma) vagas e houve a seguinte distribuição de vagas: 5.740 (cinco mil, setecentas e quarenta) vagas para o Sistema Universal (SU); 1.951 (um mil, novecentos e cinquenta e uma) vagas para o Sistema de Reserva de Vagas para Educação Básica Pública (SRVEBP). Destas, 595 (quinhentas e noventa e cinco) vagas foram destinadas aos candidatos que se autodeclararem pretos, pardos ou indígenas (SRVEBP+PPI). Considerando os dados de 2014 e 2015, o total de ingressantes na UNESP neste período foi de 15.370 estudantes. Pelo SRVEBP, ingressaram 3.148 estudantes. Deste total, 1.007 foram reservadas para pretos, pardos e índios.

Com a política de inclusão, cada vez mais, uma grande parcela de estudantes que ingressará na UNESP virá de escolas públicas e de famílias com renda per capita familiar de até 1,5 salários mínimos. Desse modo, se intensifica a hipótese de que a inclusão é um dos fatores que contribuí para reforçar o perfil de vulnerabilidade socioeconômica dos estudantes da universidade. Em função deste perfil, não se pode negligenciar que a política de inclusão, para se consolidar de fato como inclusiva, e não 
apenas como mecanismo de ingresso no ensino superior, deve ser acompanhada de outras ações afirmativas que possibilitem ao estudante concluir o curso. Trata-se da necessidade de um conjunto de ações articuladas que incluem auxílios socioeconômicos e novas estratégias pedagógicas que tenham como paradigma a diversidade e que possam favorecer a criação de uma "cultura de emancipação".

Finalmente, cabe ressaltar que, para desenvolver políticas afirmativas consolidadas é preciso que se faça um acompanhamento da realidade de cada aluno que ingressou no sistema inclusivo. Por isso, é fundamental a realização de estudos que desvendem a diversidade e complexidade desta nova realidade. Nesse sentido, estamos realizando um estudo descritivo que, a nosso ver, poderá contribuir para os debates sobre as políticas afirmativas no ensino superior e oferecer subsídios para que a UNESP possa aperfeiçoar seu projeto de inclusão e seu Programa de Permanência Estudantil.

Até o presente momento, as reflexões preliminares realizadas possibilitam apontar alguns resultados positivos e indicam que são necessárias ações institucionais integradas para se manter uma política inclusiva digna e condizente com os princípios de qualidade que devem orientar os serviços de uma universidade pública.

\title{
THE INCLUSION PROGRAM AT SÃO PAULO STATE UNIVERSITY: VALUES, CONTRADICTIONS AND AFFIRMATIVE ACTION
}

\begin{abstract}
This article has a wider aim to make a reflection about the process of affirmative policies implantation at University Teaching. More specifically, it aims to describe and done some notes about the Inclusion Project developed by Paulista State University (UNESP), since 2014, using the System of Vacancies Reservation of Public Basic Education. With this perspective, we introduce datas about the inclusive process, the profile of students and actions which are focused to students' permanency that support the inclusion at UNESP. At Least, we shows a sketch of an in progress research which has the objective to understand and evaluate the impacts and consequences of this inclusion process. The previews reflections performed allow to point some positive results and indicate that there are required integrated institutional actions to keep a worthy inclusive policy which are befitting with the quality principles that should guide the services at a public university.
\end{abstract}

Key words: Affirmative actions. Inclusion. University teaching. Student permanency. UNESP. 


\section{REFERÊNCIAS}

AZEVEDO, T. C. A. M. Análise do perfil socioeconômico e da origem administrativa do ensino médio dos alunos matriculados no $1^{\circ}$ ano dos cursos de graduação da Unesp. São Paulo: Fundação VUNESP. 2015.

BRASIL. Decreto $n^{\circ} 7.234$, de 19 de Julho de 2010. Dispõe sobre o Programa Nacional de Assistência Estudantil - PNAES. Diário Oficial da União, Brasília, DF, 20 jul. 2010. Disponível em: <http://www.planalto.gov.br/ccivil_03/_ato2007-

2010/2010/decreto/d7234.htm>. Acesso em: 25 abr. 2016.

. Lei $\mathrm{n}^{\mathrm{o}}$ 12.288, de 20 de Julho de 2010. Institui o Estatuto da Igualdade Racial.

Diário Oficial da União, Brasília, DF, 21 jul. 2010. Disponível em

<https://www.planalto.gov.br/ccivil_03/_ato2007-2010/2010/lei/112288.htm> Acesso em: 23 abr. 2016.

Lei $\mathrm{n}^{\circ}$ 12.711, de 29 de Agosto de 2012. Dispõe sobre o ingresso nas

universidades federais e nas instituições federais de ensino técnico de nível médio e dá outras providências. Diário Oficial da União, Brasília, DF, 30 ago. 2012. Disponível em: <https://www.planalto.gov.br/ccivil_03/_ato2011-2014/2012/lei/112711.htm>. Acesso em: 23 abr. 2016.

CERVI, E.U. Ações afirmativas no vestibular da UFPR entre 2005 e 2012. Revista Brasileira de Ciência Política, Brasília, n.11, p.63-88, mai./ago. 2013. Disponível em: <http://www.scielo.br/scielo.php?pid=S010333522013000200003\&script =sci_arttext $>$. Acesso em: 29 abr. 2016.

COSTA, S.G. A permanência na educação superior no Brasil: uma análise das políticas de assistência estudantil. IX COLÓQUIO INTERNACIONAL SOBRE GESTÃO UNIVERSITÁRIA NA AMÉRICA DO SUL, 2009, Florianópolis. Anais... Florianópolis: UFSC, 2009. Disponível em: 〈https://goo.gl/MJVb9S〉. Acesso em: 26 abr. 2016.

LIMA, M. E. O.; NEVES, P. S. C.; BACELLAR E SILVA, P. A implantação de cotas nas universidades: paternalismo e ameaça à posição dos grupos dominantes. Revista Brasileira de Educação, Rio de Janeiro, v.19, n.56, jan./mar. 2014. Disponível em: $<$ http://www.scielo.br/scielo.php?pid=S1413-

24782014000100008\&script=sci_abstract\&tlng=pt>. Acesso em: 23 abr. 2016.

MELLO, L.; GONÇALVES, E. Diferença e interseccionalidade: notas para pensar práticas em saúde. Revista Cronos, Natal, v.11, n.2, nov. 2010. Disponível em: <http://www.periodicos.ufrn.br/cronos/article/view/2157 >. Acesso em: 26 abr. 2016.

MENDES JUNIOR, A. A. F. Uma análise da progressão dos alunos cotistas sob a primeira ação afirmativa brasileira no ensino superior: o caso da Universidade do Estado do Rio de Janeiro (UERJ). Ensaio: Avaliação e Políticas Públicas em Educação, Rio de Janeiro, v.22, n.82, p.31-56, jan./mar. 2014. Disponível em: <http://www.scielo.br/pdf/ensaio/v22n82/a03v22n82.pdf>. Acesso em: 23 abr. 2016.

MENIN, M. S. S. et al. Representações de estudantes universitários sobre alunos cotistas: confronto de valores (UNESP/Marília). Educação e Pesquisa, São Paulo, v.34, 
n.2, p.255-272, mai./ago. 2008. Disponível em:

<http://base.repositorio.unesp.br/handle/11449/26683?locale-attribute=en>. Acesso em: 23 abr. 2016.

NEVES, C. E. B.; RAIZER, L.; FACHINETTO, R. F. Acesso, expansão e equidade na educação superior - novos desafios para a política educacional brasileira. Sociologias, Porto Alegre, ano 9, n.17, p.145-157, jan./jun. 2007. Disponível em:

<http://www.scielo.br/pdf/soc/n17/a06n17>. Acesso em: 23 abr. 2016.

QUERINO, A. C. et al. Guia de Enfrentamento do Racismo Institucional. [S.1.]:

Geledés - Instituto da Mulher Negra, Ibraphel Gráfica, 2013. Disponível em:

<http://www.onumulheres.org.br/wp-content/uploads/2013/12/Guia-de-enfrentamentoao-racismo-institucional.pdf $>$. Acesso em: 23 abr. 2016.

SOUZA, M. A. Desempenho dos candidatos no vestibular e o sistema de cotas na UERJ. Ensaio: Avaliação e Políticas Públicas em Educação, Rio de Janeiro, v.20, n.77, p.701-724, out./dez. 2012. Disponível em:

<http://www.scielo.br/pdf/ensaio/v20n77/a05v20n77.pdf>. Acesso em: 25 nov. 2014.

RISTOFF, D. O novo perfil do campus brasileiro: uma análise do perfil socioeconômico do estudante de graduação. Avaliação, Sorocaba, v.19, n.3, p.723-747, nov. 2014.

SÃO PAULO (Estado). Universidade Estadual Paulista. Assessoria Especial de Planejamento Estratégico. Anuário Estatístico. São Paulo: UNESP, 2015. Disponível em: <https://ape.unesp.br/anuario/ pdf/Anuario2015_NOVO.pdf>. Acesso em: 25 abr. 2016.

VASCONCELOS, M. S.; GALHARDO, E. Impacto financeiro do programa de inclusão e de permanência estudantil na UNESP. São Paulo: Coordenadoria de Permanência Estudantil UNESP, 2015a. Disponível em:

<http://www.unesp.br/Home/proex/permanenciaestudantil/ impacto_coordenadoria-deensino-superior.pdf >. Acesso em: 24 abr. 2016.

Relatório sobre as atividades desenvolvidas pela Coordenadoria de Permanência Estudantil na UNESP. São Paulo: Coordenadoria de Permanência Estudantil UNESP, 2014.

Relatório sobre as atividades desenvolvidas pela Coordenadoria de Permanência Estudantil na UNESP. São Paulo: Coordenadoria de Permanência Estudantil UNESP, 2015b. Disponível em: <http://www.unesp.br/Home/proex/ permanenciaestudantil/relatorio_cope_2015.pdf>. Acesso em: 25 abr. 2016.

VASCONCELOS, S. D.; SILVA, E. D. G. Acesso a universidade pública através de cotas - uma reflexão a partir da percepção dos alunos de um pré-vestibular inclusivo. Ensaio: Avaliação e Políticas Públicas em Educação, Rio de Janeiro, v.13, n.49, p.453-468, out./dez. 2005. Disponível em:

<http://www.scielo.br/scielo.php?script=sci_arttext\&pid=S0104-40362005000400004>. Acesso em: 23 abr. 2016.

VELLOSO, J. C. Cotistas e não-cotistas: rendimento de alunos da Universidade de Brasília. Cadernos de Pesquisa, São Paulo, v.39, n.137, p.621-644, ago. 2009. 
Disponível em: <http://www.scielo.br/scielo.php?script=sci_arttext\&pid=S010015742009000200014 \&lng=em \&nrm=iso>. Acesso em: 16 dez. 2015.

VIBETTO, A. (Org.). Políticas, poéticas e práticas pedagógicas. Rio de Janeiro: Lamparina, 2014.

ZAGO, N. Do acesso à permanência no ensino superior: percursos de estudantes universitários de camadas populares. Revista Brasileira de Educação, Rio de Janeiro, v.11, n.32, p.226-237, ago. 2006. Disponível em: <http://www.scielo.br/ scielo.php?script=sci_arttext\&pid=S1413-24782006000200003\&lng=en\&nrm=iso $>$. Acesso em: 26 abr. 2016.

WINTHER, J. M.; GOLGHER, A. B. Uma investigação sobre a aplicação de bônus adicional como política de ação afirmativa na Universidade Federal de Minas Gerais (UFMG). Revista Brasileira de Estudos de População, Rio de Janeiro, v.27, n.2, p.333-359, jul./dez. 2010. Disponível em:

<http://www.scielo.br/pdf/rbepop/v27n2/07.pdf>. Acesso: 25 abr. 2016. 